\title{
Platelet-Rich Fibrin is a Bioscaffold and Reservoir of Growth Factors for Tissue Regeneration
}

\author{
Young-Ho Kang, D.D.S., M.S., ${ }^{1,}$ Soung Hoo Jeon, Ph.D., ${ }^{1,2,{ }^{*}}$ Joo-Young Park, D.D.S., ${ }^{1,2}$ \\ Jong-Hoon Chung, Ph.D., ${ }^{3}$ Yun-Hoon Choung, D.D.S., M.D., Ph.D., ${ }^{4}$ Han-Wool Choung, D.D.S., M.S., \\ Eun-Suk Kim, D.D.S., Ph.D., and Pill-Hoon Choung, D.D.S., Ph.D.,
}

The platelet-rich fibrin (PRF) is known as a rich source of autologous cytokines and growth factors and universally used for tissue regeneration in current clinical medicine. However, the microstructure of PRF has not been fully investigated nor have been studied the key molecules that differ PRF from platelet-rich plasma. We fabricated PRF under Choukroun's protocol and produced its extract (PRFe) by freezing at $-80^{\circ} \mathrm{C}$. The conventional histological, immunohistological staining, and scanning electron microscopy images showed the microstructure of PRF, appearing as two zones, the zone of platelets and the zone of fibrin, which resembled a mesh containing blood cells. The PRFe increased proliferation, migration, and promoted differentiation of the human alveolar bone marrow stem cells (hABMSCs) at $0.5 \%$ concentration in vitro. From the results of proteome array, matrix metalloproteinase 9 (MMP9) and Serpin E1 were detected especially in PRFe but not in concentrated platelet-rich plasma. Simultaneous elevation of MMP9, CD44, and transforming growth factor $\beta-1$ receptor was shown at $0.5 \%$ PRFe treatment to the hABMSC in immunoblot. Mineralization assay showed that MMP9 directly regulated mineralization differentiation of hABMSC. Transplantation of the fresh PRF into the mouse calvarias enhanced regeneration of the critical-sized defect. Our results strongly support the new characteristics of PRF as a bioscaffold and reservoir of growth factors for tissue regeneration.

\section{Introduction}

$\mathbf{T}$ HE PLATELET-RICH FIBRIN (PRF) is known as a rich source of autologous cytokines and growth factors, and special attention has been paid as a new biomaterial in clinical application. Fabrication protocol of PRF is relatively simple and natural, as it is the outcome product of short centrifugation of autogenous blood without usage of anticoagulant or bovine platelet activators. Ahead of PRF, platelet-rich plasma (PRP) was introduced in 1998 and its classic protocol was provided as blood collection with anticoagulant, two steps of centrifugation, and artificial polymerization of the platelet concentrate. ${ }^{1}$ However, the real efficacy of PRP has been debated, although its release of the growth factors from the platelets was proven. ${ }^{1}$ PRF was introduced in the meantime as a new generation of platelet concentrate by Choukroun et al. for specific use in oral and maxillofacial surgery. ${ }^{2}$ Its fabrication protocol minimized blood manipulation, eliminated an- ticoagulant usage, simplified centrifugation into single step, and used natural fibrin clot polymerization.

PRF was known to enhance bone formation and, in particular, to increase the healing rate of grafted bone. Evidence for the clinical application was shown in sinus lifting, alveolar bone defect for implant installation. ${ }^{3}$ Application of PRF for the reconstruction of maxillofacial defects resulted in quicker maturation and consolidation of autogenous bone transplant and higher bone density. Further, the combination of PRF and autogenous bone increased the rate of osteogenesis and the quality of the new bone. ${ }^{4,5}$

Previous studies reported that these clinical effects came from the cytokines and growth factors released during PRF production by centrifugation, as platelets were activated and their massive degranulation implied significant cytokine release. ${ }^{6}$ The known cytokines and growth factors in PRF included interleukin-1 $\beta$ (IL-1 $\beta$ ), IL-4, tumor necrosis factor $\alpha$, platelet-derived growth factor $\alpha$ and $\beta$ (PDGF- $\alpha$ and $\beta$ ),

\footnotetext{
${ }^{1}$ Department of Oral and Maxillofacial Surgery, Dental Research Institute, School of Dentistry, Seoul National University, Seoul, Korea.

${ }^{2}$ Tooth Bioengineering National Research Laboratory, BK21, School of Dentistry, Seoul National University, Seoul, Korea.

${ }^{3}$ Department of Biosystems and Biomaterials Science and Engineering, College of Agriculture and Life Science, Seoul National University, Seoul, Korea.

${ }^{4}$ Department of Otolaryngology, School of Medicine, Ajou University, Suwon, Korea.

${ }^{5}$ Department of Oral and Maxillofacial Surgery, School of Medicine, Choongnam National University, Tae-jun, Korea.

*These two authors contributed equally to this work.
} 
transforming growth factor- $\beta 1$ (TGF- $\beta 1$ ), insulin-like growth factors 1 (IGF-1), and vascular endothelial growth factor (VEGF). ${ }^{6-9}$ Among them, TGF- $\beta 1$, PDGF-AB, VEGF, and thrombospondin-1 are known as the typical growth factors released from PRF with highest amounts, promoting the healing of soft and hard tissues through stimulation of collagen production to improve wound strength and initiation of callus formation. ${ }^{7,10-13}$ However, other important factors may exist in the upstream of PDGF-AB and TGF- $\beta 1$ in the wound healing mechanism of PRF, as cytokine and growth factor arrays have not been carried out for PRF so far.

PRF was suggested to have very different effects from concentrated PRP (cPRP), which would have a massive, uncontrollable, and short-term effect. ${ }^{14}$ The two times centrifuged PRP was defined as CPRP and it was one of the most frequently used form of PRP in clinical application. ${ }^{15}$ However, the real efficacy of cPRP was debated and some studies concluded that CPRP mediated only the early aspects of the bone repair process. ${ }^{16-19}$ On the other hand, PRF released autologous growth factors gradually and expressed stronger and more durable effect on the cellular proliferation and differentiation than CPRP in vitro, shown by the recent study undergone in rat osteoblasts. ${ }^{20}$ Several reasons were suggested for these differences, but the unique characteristics of PRF have never been investigated.

In this study, we report the new distinct property of PRF as a bioscaffold through investigating the microstructure by histological, immunohistological, and scanning electron microscopy (SEM) observations. To examine the proliferative and differentiative effect of PRF, the fresh PRF was frozen at $-80^{\circ} \mathrm{C}$ and its extract was obtained. BromodeoxyUridine (BrdU) incorporation and wound healing assay were performed to test direct or indirect proliferation effect of PRF extract (PRFe) on the human alveolar bone marrow stem cells (hABMSCs), whereas mineralization was induced with or without PRFe to examine mineralization differentiation effect in vitro. We also show the upstream molecules of tissue healing mechanisms, which differentiate PRF from cPRP by proteome profiler arrays. Besides, the fresh PRF was transplanted into the mouse calvarias critical-sized defect to confirm the regeneration capacity of PRF in vivo.

\section{Materials and Methods}

Human peripheral blood collection and PRF, PRFe, and $c P R P$ fabrication

The venous blood of a volunteer, who was healthy and not taking any medication, was drawn under sufficient informed consent and protocol approved by institutional review board at the Seoul National University Dental Hospital, Seoul, South Korea. The following PRF production was referred to the protocol by Choukroun et al. ${ }^{2,21}$ Briefly, the blood sample was taken in $10 \mathrm{~mL}$ tubes without anticoagulant and then immediately centrifuged at $400 \mathrm{~g}$ for $10 \mathrm{~min}$. A fibrin clot was obtained in the middle height of the tube between the red corpuscles at the bottom and the acellular plasma at the top. The obtained fibrin clot was defined as PRF. Then, the PRF was frozen at $-80^{\circ} \mathrm{C}$ for $1 \mathrm{~h}$ to separate trapped growth factors and cytokines from the fibrin meshes. The leaked juice was harvested without fibrin fibers by centrifugation at $230 \mathrm{~g}$ for $10 \mathrm{~min}$ and called as the PRF extract (PRFe). The remained fibrin clot was called frozen PRF.
As for the CPRP, the same venous blood was used as PRF fabrication following the protocol from the department of laboratory medicine, Blood Bank, Seoul National University Hospital. Briefly, $320 \mathrm{~mL}$ withdrawn blood was initially centrifuged at $2000 \mathrm{rpm}$ for $7 \mathrm{~min}$ to separate PRP and plasma-poor plasma (PPP) portions from the red blood cell fraction. The PRP and PPP portions were again centrifuged at $2900 \mathrm{rpm}$ for $10 \mathrm{~min}$ to separate PRP from PPP. The twotime centrifuged PRP was defined as cPRP. ${ }^{15}$ The number of platelets in PRP was adjusted to $1063 \times 10^{3} / \mu \mathrm{L}$ after PRP was collected. The PRP samples were stored in conical tubes at $-70^{\circ} \mathrm{C}$. After three cycles of freezing-thawing to release the growth factors contained in platelets, PRP was ready to be applied to each cultures.

\section{Isolation of $h A B M S C s$}

Alveolar bone marrow in human mandible was obtained from the extraction socket of young adults at the Department of Oral and Maxillofacial Surgery, under sufficient informed consent and protocol also approved by institutional review board at the Seoul National University Dental Hospital, Seoul, South Korea. Separated tissues were digested in a solution of $3 \mathrm{mg} / \mathrm{mL}$ collagenase type I (Worthington Biochem) and $4 \mathrm{mg} / \mathrm{mL}$ dispase (Boehringer) for $1 \mathrm{~h}$ at $37^{\circ} \mathrm{C}$. Single-cell suspensions were obtained by passing the cells through a $40 \mu \mathrm{m}$ strainer (Falcon). Single-cell suspensions were cultured in Minimum Essential Medium-Alpha ( $\alpha$-MEM) (Gibco BRL) supplemented with $10 \%$ fetal bovine serum (Equitech-Bio Inc), $100 \mu \mathrm{M}$ ascorbic acid 2-phosphate (Wako), $2 \mathrm{mM}$ glutamine, $100 \mathrm{U} / \mathrm{mL}$ penicillin, and $100 \mu \mathrm{g} / \mathrm{mL}$ streptomycin (Biofluids), and then incubated at $37^{\circ} \mathrm{C}$ in $5 \% \mathrm{CO}_{2}$. All primary cells used in this study were at passages 2 or 3 .

\section{Histological examination}

To identify microstructure of PRF, the fresh PRF and the frozen PRF were observed by histological examination. The specimens were fixed in $3.7 \%$ paraforaldehyde for 1 week at $4{ }^{\circ} \mathrm{C}$. Then, $4-\mu \mathrm{m}$-thick serial sections were cut transversely at the center of the exposed site. The sections were then processed for hematoxylin and eosin (H\&E) staining. Immunohistochemical staining was also performed on the fresh and the frozen PRF. Briefly, 4- $\mu \mathrm{m}$-thick paraffin sections were de-paraffinized and hydrated with alcohol series. After antigen retrieval in citrate buffer, the sections were treated with hydrogen peroxide. After blocking with 1\% bovine serum albumin in phosphate-buffered saline (PBS) for overnight at $4{ }^{\circ} \mathrm{C}$, the whole-mounted specimens were incubated for $2 \mathrm{~h}$ at room temperature with anti-platelet activating receptor antibody (rabbit clone H963, 1:200; Abcam) for detection of platelet, and anti-fibronectin fiber antibody for detection of fibrin (rabbit, 1:200; Abcam). After several PBS washes, the specimens were incubated for $1 \mathrm{~h}$ at room temperature with the following secondary antibodies: Alexa Fluor 488 antirabbit antibody or Alexa Fluor 555 anti-rabbit antibody (1:1000; Molecular Probes). Specimens were imaged by an LSM 510 META confocal laser scanning microscope (ZEISS).

\section{Scanning electron microscopy}

For SEM observations, the fresh PRF and the frozen PRF were cross sectioned and fixed as described above, rinsed in 
PBS, and dehydrated with serial concentrations of ethanol. Dehydrated specimens were gold sputter-coated and observed under the scanning electron microscope (Hitachi, S4700).

\section{Cell proliferation and migration assay}

For quantitative analysis of cell proliferation, BrdU incorporation was used. The hABMSCs were seeded at $2 \times 10^{4}$ cells per well slips in six-well plates and incubated for $24 \mathrm{~h}$ over $22 \times 22-\mathrm{mm}$ cover slips. BrdU (Roche Applied Science) was added at final concentration of $20 \mu \mathrm{M}$ with or without $0.5 \% \mathrm{PRFe}$ and the cells were further incubated for $12 \mathrm{~h}$ at $37^{\circ} \mathrm{C}$. Cells were washed twice with PBS and then fixed in $3.7 \%$ paraformaldehyde at $4^{\circ} \mathrm{C}$ for $10 \mathrm{~min}$. Cells were permeabilized with $0.1 \%$ Triton $\mathrm{X}-100$ at $4^{\circ} \mathrm{C}$ for $5 \mathrm{~min}$ and incubated with $2 \mathrm{~N} \mathrm{HCl}$ for $5 \mathrm{~min}$ and then gently washed three times with PBS. After blocking with $1 \%$ bovine serum albumin in PBS for overnight at $4^{\circ} \mathrm{C}$, cells were incubated with mouse anti-BrdU monoclonal antibody (Dako) at a 1:100 dilution for $2 \mathrm{~h}$ at room temperature, incubated with Alexa Fluor 488 anti-mouse secondary antibody at a 1:1000 dilution for $30 \mathrm{~min}$ at room temperature, and then washed five times with PBS. For nuclear staining, 4', 6'-diamidine-2'-phenylindole dihydrochloride (Roche Applied Science) was used at a final concentration of $1 \mu \mathrm{g} / \mathrm{mL}$ in PBS for $5 \mathrm{~min}$ followed by extensive washing with PBS. Cover slips were mounted and cells were viewed with a confocal imaging system as described above. Each analysis was repeated at least three times.

To observe the effect of PRFe on the cellular migration of hABMSCs, wound-healing assay was performed under an optimal condition. The control group consisted of the cells grown in the medium without PRFe and the experimental group in the medium with $0.5 \%$ PRFe. The concentration was calculated as volume percentage of added PRFe to the total volume of the cell culture medium. hABMSCs were seeded into a six-well culture plate and allowed to grow to $90 \%$ confluency in complete medium. Cell monolayers were wounded by a plastic tip $(1 \mathrm{~mm})$. Wounded monolayers were then washed four times with medium to remove cell debris and incubated in serum-free medium in the absence or present PRFe. Cell migration into the wound surface was monitored by microscopy at $0,12,24$, and $48 \mathrm{~h}$. Quantification was done by measuring the distance of the wound edge of the migrating cells from the start point to the migrated point.

\section{Mineralization induction}

The hABMSCs $\left(1 \times 10^{5}\right.$ cells/well $)$ were seeded into sixwell plates with the normal medium. The medium was changed to the mineralization induction medium $(\alpha-\mathrm{MEM}$, $5 \mathrm{mM} \beta$-glycerolphosphate, and $10 \mathrm{nM}$ dexamethason) after 3 days and $0 \%, 0.5 \%$ of PRFe, or $40 \mu \mathrm{g} / \mathrm{mL}$ matrix metalloproteinase 9 (MMP9) protein (Abcam) and/or $100 \mathrm{nM}$ MMP9 inhibitor I (Calbiochem) were added. The medium was changed every 3 days. On the days 7, 14, 21, 28, and 35, accumulation of mineral nodules was detected by $2 \%$ alizarin red S staining at $\mathrm{pH} 4.2$ (Sigma). For destaining procedure for measurement of calcium content, $3 \mathrm{~mL}$ of $10 \mathrm{mM}$ sodium phosphate-10\% acetylpyrimidium ( $\mathrm{pH}$ 7.0) solution was added to each stained well and incubated at room temperature for $15 \mathrm{~min}$. The destained sample was then transferred to a 96-well plate and the absorbance was measured at $562 \mathrm{~nm}$.

\section{Sodium dodecyl sulfate polyacrylamide gel electrophoresis}

For sodium dodecyl sulfate (SDS)-polyacrylamide gel electrophoresis (PAGE), the Laemmli buffer system was used to cast a $5 \%$ stacking gel and $6 \%$ to $15 \%$ gradient resolving gel. After denaturation at $100^{\circ} \mathrm{C}$ for $3 \mathrm{~min}$, proteins were resolved at a constant $120 \mathrm{~V}$ in a Bio-Rad mini-Protean II apparatus until the bromophenol blue reached the bottom of the gel and visualized with coomassie blue. For the highly concentrated protein bands at $250-150$ and $60-45 \mathrm{kDa}$, both samples were 20 times diluted and reloaded on the same SDS-PAGE.

\section{Focused protein array for PRFe and cPRP}

The focused protein array analysis was performed according to the manufacturer's instructions (Proteome Profiler ${ }^{\mathrm{TM}}$ Array; R\&D Systems). The human cytokine array panel $\mathrm{A}$ and the human angiogenesis array panel (Proteome Profiler Array; R\&D Systems) were used for both of PRFe and CPRP. The horseradish peroxidase-conjugated secondary antibodies incubation was followed (Santa Cruz Biotechnology) and protein spots were observed using enhanced chemiluminescence (Amersham Biosciences). The positive controls were two spots each and located in three corners, upper left, upper right, and lower left of each array kit, whereas the negative controls were also two spots but located in lower right of each array kit.

\section{Mouse calvarial defect surgery}

All animal maintenance and surgical procedures were reviewed and approved by institutional animal care and use committee (No. 050512-11, ilar.snu.ac.kr, IACUC), Seoul national university, Seoul, Korea. Six 8-10-week-old male specific pathogen-free BALB/c nude mice were used for this study (Jackson Laboratory). All mice were anesthetized with intraperitoneal injection of combination of anesthetics $(1 \mathrm{~g}$, 2,2,2-tribromoethanol and $0.63 \mathrm{~mL}, 2$-methyl-2-butanol in $100 \mathrm{~mL}$ PBS, $30 \mu \mathrm{L} / \mathrm{g}$ body weight) and 4 -mm-diameter round defect was made with a trephine bur in the unilateral nonsuture-associated parietal under constant irrigation. Four-millimeter defect was thought to be critical in mouse calvarias. ${ }^{22}$ Extreme care was taken to avoid injury to the underlying dura mater. Each defect was rinsed with saline to remove bone debris and the fresh PRF cut in $4 \mathrm{~mm}$ diameter was implanted in the defect (PRF group, $n=3$ ). Nothing was implanted in the control group $(n=3)$. After placement of the PRF or nothing, the skin was sutured closed and the animal was monitored.

\section{Microcomputed tomography imaging and histological analysis of mouse calvaria}

Samples were harvested 8 weeks after surgical implantation. Calvaria were fixed in $3.7 \%$ paraformaldehyde for 1 week at $4^{\circ} \mathrm{C}$. Representative skulls were trimmed to the proper size for the analysis chamber of the $\mu \mathrm{CT}$ device (SkyScan1172 high-resolution micro-CT), and mounted on a 


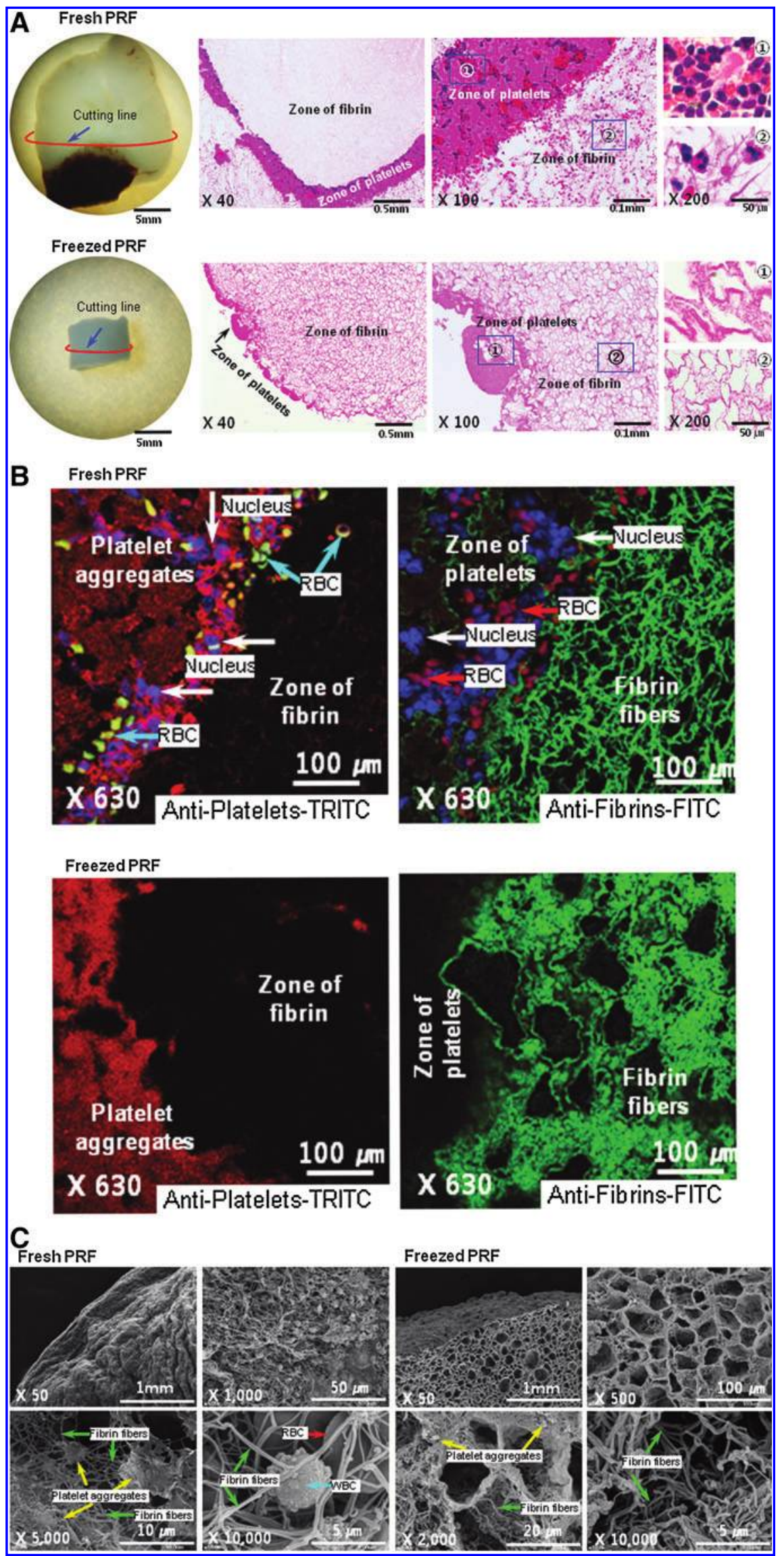


turntable that could be shifted automatically in the axial direction. Six hundred projections were taken over 180 of object rotation (0.3 degree). The $\mathrm{X}$-ray shadow projections were digitized as $1024 \times 1024$ pixels with 4096 brightness gradations (12 bit) for cooled camera or 256 gradations (8 bit). The spatial resolution obtained was $15 \mu \mathrm{m}$.

The samples were then trimmed for decalcification $10 \%$ EDTA for 3 weeks and embedded in paraffin. Fourmicrometer serial bucco-lingual sections were stained with $\mathrm{H} \& \mathrm{E}$ and examined under light microscope. (Olympus U-SPT).

\section{Statistical analysis}

Data are expressed as mean \pm standard deviation. Statistical significance of differences between the groups was analyzed by Student's $t$-test. A $p$-value of $<0.05$ was considered statistically significant $(p \leq 0.05)$.

\section{Results}

\section{PRF acts as a reservoir of cytokines and a possible scaffold for tissue regeneration}

To determine whether the fresh PRF contains phenotypic blood cells such as leukocyte, monocyte, platelet, and fibrin fibers, histological analysis was performed. Two distinct zones were observed in H\&E-stained fresh PRF, the zone of platelets, and the zone of fibrin. In the zone of platelets, highly concentrated platelets were observed in dark-purple color, whereas cross-linking mesh-like structure with various blood cells were observed in pink color in the zone of fibrin (Fig. 1A, upper panel). In frozen PRF, the distinct two zones existed same as fresh PRF, but no blood cells were observed in the zone of fibrin. Strong contraction during freezing process could remove the blood cells (Fig. 1A, lower panel).

To localize platelets and fibrin fibers, fluorescence immunohistochemical analysis was used. In the fresh PRF, the existence of platelets was verified with anti-platelet activity receptor antibody at the zone of platelet (Fig. 1B, upper panel; the particulate forms are marked by a white arrow). The platelet aggregates were mostly condensed at the center with many other blood cells, whose nuclei were stained with $4^{\prime}, 6^{\prime}$-diamidine-2'-phenylindole dihydrochloride. This structure implied the function of PRF as a reservoir containing blood cells and cytokines. Various blood cells were capable of residing in PRF, secreting cytokines long-term, which may contribute to tissue regeneration. Localization of the fibrin fibers were confirmed with anti-fibronectin antibody and the fibrins were reticulated with each other at the mesh-shaped area. In the frozen PRF, however, platelets and fibrin fibers existed at each zone but no cells were detected (Fig. 1B, lower panel).

In the enlarged images by SEM, long and narrow fibrin fibers were observed covering the platelet aggregates and interconnecting with each other to the inside. Erythrocytes and leukocytes were involved in the fiber network. In contrast, frozen PRF showed highly condensed fibrin fiber network with platelet aggregates but without other blood cells, which resembled a honeycomb having many small cells (Fig. 1C). This microstructure of PRF indicated its innate scaffold characteristics, physically and biologically satisfied several properties of the ideal scaffold, and supported the clinical outcomes of tissue regeneration.

\section{PRFe activates cellular proliferation and inhibits motility of $h A B M S C S$}

To determine how PRF influence on cellular physiology in vitro, the percentage of BrdU incorporation was measured in control hABMSCs and PRFe-treated hABMSCs for proliferation evaluation. The relative numbers of BrdU-positive cells were increased about $40 \%$ by PRFe treatment, implying positive effect on cellular proliferation of PRFe (Fig. 2A). However, PRFe had inhibitory effect on cell migration, shown by wound-healing assay. Confluent monolayers of cells were scratched to form wound and cultured in the absence or presence of $0.5 \%$ PRFe at the $0,12,24$, and $48 \mathrm{~h}$ and then phase-contrast images were photographed. The migration distances were measured between the leading edge and the wound line. After $24 \mathrm{~h}$, the cells in control group efficiently spread into the wound area, whereas few cells in PRFe-treated group spread forward (Fig. 2B). The migration rate was lower in the PRFe-treated group by $20 \%$ at $24 \mathrm{~h}$ and $19 \%$ at $48 \mathrm{~h}$ than in the control group. This implies that the ABMSCs tend to aggregate and not to migrate under the PRFe treatment.

\section{PRFe activates mineralization of hABMSCs}

The effect of PRFe on mineralization of hABMSCs was studied by alizarin red staining. The hABMSCs was cultured under the normal medium or mineralization induction medium, with or without treatment of PRFe. During 5 weeks of mineralization induction, the PRFe-treated hABMSCs

FIG. 1. Microstructure of fresh PRF and frozen PRF. (A) The left upper and lower panel showed fresh PRF and frozen PRF, respectively, in $3.7 \%$ paraformaldehyde fixatives. The specimens were cut in the red horizontal circle and the cross sections were stained with hematoxylin and eosin. The fresh PRF showed two distinct zones, the zone of platelets and the zone of fibrin. In the zone of platelets, highly concentrated platelets were observed in dark purple color in magnified view give link, whereas cross-linking mesh-like structure with various blood cells was observed in pink color in the zone of fibrin give link. In the frozen PRF, however, two zones existed same as the fresh PRF, but no blood cells were observed (lower figures). (B) The immunofluorescence staining showed the existence of platelets with anti-platelet activity receptor antibody at the zone of platelet (red) and fibrin fibers with anti-fibronectin antibody (green), whereas blood cell nuclei were stained with $4^{\prime}, 6^{\prime}-$ diamidine-2'-phenylindole dihydrochloride. Various blood cells were shown in fresh PRF but no cells were detected in frozen PRF. Scale bars were $100 \mu \mathrm{m}$. (C) Scanning electron microscopy images of fixed fresh PRF and frozen PRF showed platelet aggregates (yellow arrows) and fibrin fibers (green arrows). Long and narrow fibrin fibers covered the platelet aggregates and interconnected with each other to the inside. Erythrocytes (red arrows) and leukocytes (blue arrows) were involved in the fiber network only in fresh PRF. Frozen PRF showed highly condensed fibrin fiber network with platelet aggregates but no blood cells, which resembled a honeycomb having many small cells. PRF, platelet-rich fibrin. Color images available online at www.liebertonline.com/ten. 
showed far more mineral nodules formation compared to the cells without PRF treatment at the same week (Fig. 2C). To analyze the data quantitatively, alizarin red-stained samples were de-stained and the absorbance was measured at $565 \mathrm{~nm}$ of wavelength. As a result, calcium content was higher in the PRF-treated group but also the cells were comparatively more proliferated in the PRF-treated group than the cells in the control group (data not shown).

\section{Evaluation of the results from proteome profiler arrays}

Cytokines and growth factor are extracellular signaling molecules that mediate cell-to-cell communication. They are also released from the blood cells and play essential roles in many biological processes such as cellular growth, differentiation, migration, immunity, and inflammation. In the most biological processes, multiple cytokines operate in a large

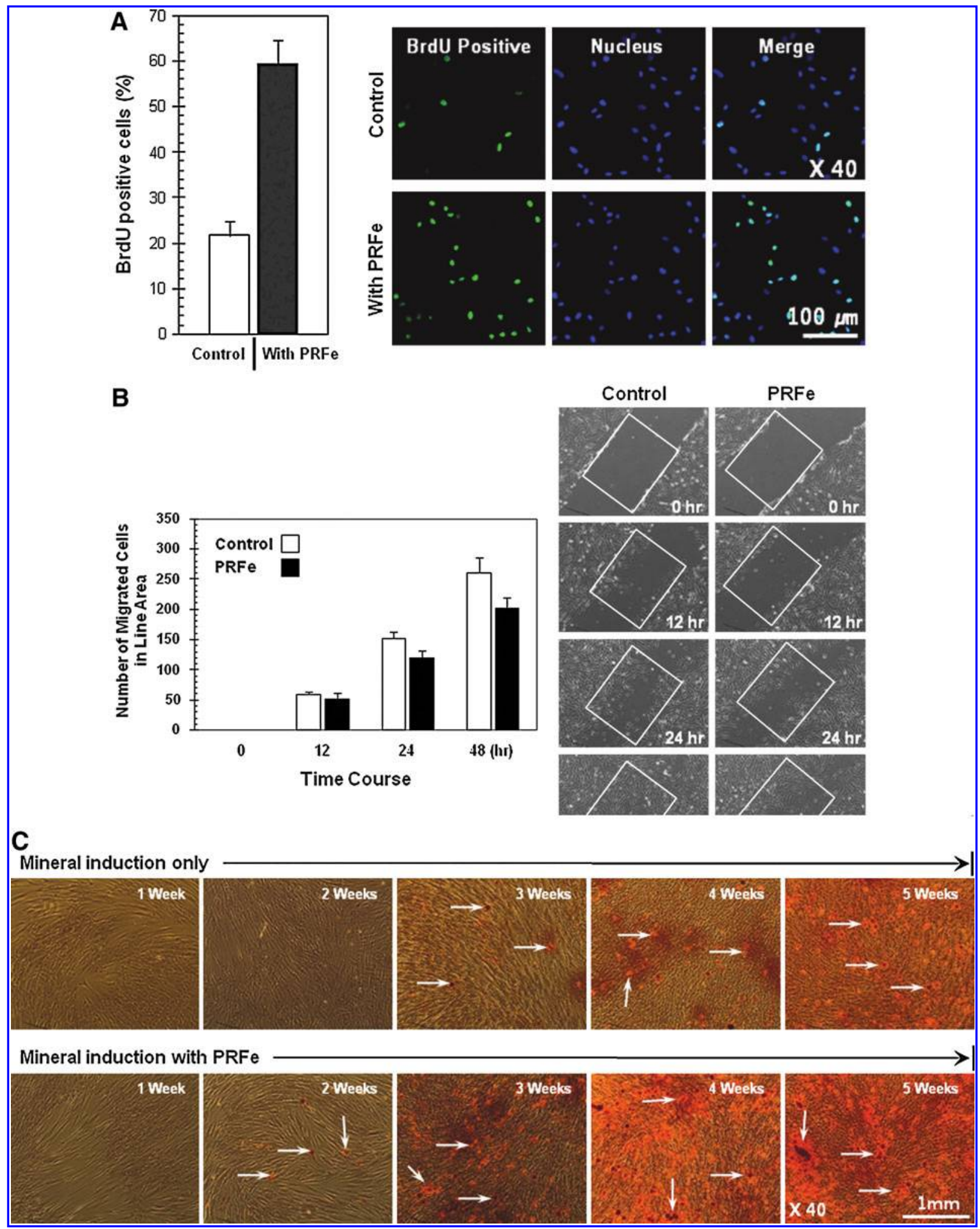


network, where the action of one cytokine is regulated by presence or absence of other cytokines. ${ }^{23,24}$ The PRFe and cPRP, fabricated in $8 \mathrm{~h}$ from isolation of blood collection, were assayed with the human cytokine array panel $\mathrm{A}$ and human angiogenesis array kit (R\&D systems) according to the manufacturer's instructions.

To identify the variety of protein profiles of PRFe and cPRP, both extracts were loaded on the gradient SDS-PAGE gel and the coomassie blue-stained bands were analyzed. Different band pattern was noticed between the PRFe and the CPRP, indicating that some unique proteins may exist only in PRFe (Fig. 3A, arrow heads).

The protein array kits that consisted of 36 cytokines and 55 angiogenesis related proteins were used for human PRFe and cPRP (Fig. 3B). The 36 cytokines included C5a, CD40 Ligand, G-CSF, GM-CSF, GRO $\alpha$, I-309, sICAM- 1 , IFN- $\gamma$, IL- $1 \alpha$, IL-1 $\beta$, IL-1ra, IL-2, IL-4, IL-5, IL-6, IL-8, IL-10, IL-12p70, IL-13, IL16, IL-17, IL-17E, IL-23, IL-27, IL- 32 $\alpha$, IP-10, I-TAC, MCP-1, MIF1, MIP- $1 \alpha$, MIP-1 $\beta$, Serpin E1, RANTES, SDF-1, TNF $\alpha$, and sTREM-1. The 55 angiogenesis-related proteins included Activin A, ADAMTS-1, Angiogenin, Angiopoietin-1, Angiopoietin-2, Angiostatin/Plasminogen, Amphiregulin, Artemin, Coagulation Factor III, CXCL16, DPPIV, EGF, EGVEGF, Endoglin, Endostatin/Collagen XVIII, Endothelin-1, fibroblast growth factor (FGF) acidic, FGF basic, FGF-4, FGF7, GDNF, GM-CSF, HB-EGF, HGF, IGFBP-1, IGFBP-2, IGFBP-3, IL-1 $\beta$, IL-8, LAP (TGF- $\beta 1$ ), Leptin, MCP-1, MIP-1 $\alpha$, MMP-8, MMP-9, NRG1- $\beta 1$, Pentraxin 3 (PTX3), PD-ECGF, PDGF-AA, PDGF-AB/PDGF-BB, Persephin, Platelet Factor 4 (PF4), PlGF, Prolactin, Serpin B5, Serpin E1, Serpin F1, TIMP1, TIMP-4, Thrombospondin-1, Thrombospondin-2, uPA, Vasohibin, VEGF, and VEGF-C.

The cytokine and the angiogenesis-related protein arrays revealed that nine factors were highly expressed in PRFe: angiogenin, IGFBP-2, IGFBP-3, MMP9, Serpin E1, TIMP-1, sICAM-1, MIF1, and RANTES/CCL5 (Fig. 3B, upper panel, white and red arrowheads). However, in CPRP, MMP9 and Serpin E1 were not detected, although other seven factors were expressed (Fig. 3B, lower panel, white arrowheads). These results suggested that MMP9 and Serpin E1 might play important roles in PRF-induced tissue regeneration. MMPs are known to function when cells migrate through the extracellular matrix and CD44 to act as a docking molecule for MMP9 on the cell surface, suggesting a mechanism of CD44-mediated cell migration. ${ }^{25-28}$ To identify involvement of MMP9 in CD44's regulation mechanism in PRF, we measured the level of MMP9 and CD44 after 0.5\% PRFe treatment to the hABMSCs in time course. Immunoblot showed increased CD44 level, with simultaneous increase of MMP9 in 24h after addition of $0.5 \%$ PRFe (Fig. 3C). In addition, TGF- $\beta 1$ expression was evaluated in the hABMSCs in $24 \mathrm{~h}$ after addition of $0.5 \% \mathrm{PRFe}$, as platelets were known to contain key growth factors, such as PDGF-AB, TGF- $\beta 1$, and VEGF, which were able to stimulate cell proliferation, matrix remodeling, and angiogenesis..$^{29,30}$ The level of TGF- $\beta 1$ receptor was also increased according to the increase of MMP9 and CD44 (Fig. 3C).

\section{MMP9 in PRF is a key factor in mineralization of hABMSCs}

To assess whether MMP9 contribute to mineralization of hABMSCs, we treated recombinant MMP9 protein (rMMP9) on the hABMSCs. The extent of mineralization was confirmed by formation of mineral nodules stained by alizarin red. The effects of rMMP9 were compared, in each case with rMMP9 alone, rMMP9 with MMP9 inhibitor, PRFe alone, or PRFe with MMP9 inhibitor under the mineralization induction condition. The hABMSCs cultured at $40 \mathrm{ng} / \mathrm{mL}$ rMMP9 or $0.5 \%$ PRFe in 3 weeks showed far higher mineralization than $0 \%$ rMMP9 or $0 \%$ PRFe. On the other hand, the hABMSCs cultured with rMMP9 plus 100 nM MMP9 inhibitor showed reduced mineralization. MMP9 inhibitor also reduced mineralization effect of $0.5 \%$ PRFe. These results suggested that MMP9 in PRFe played a crucial role in mineralization differentiation of hABMSCs (Fig. 4, right panels). The calcium content measured from the destained samples followed the same trend as the results of alizarin red-stained samples (Fig. 4, left graph).

\section{PRF activates regeneration of critical-sized mouse calvarial defects}

The results of microcomputed tomography and histological analysis showed that the defect size of the control group (no transplantation group, $n=3$ ) remained larger than the size of the experimental group (fresh PRF transplantation group, $n=3$ ) at 8 weeks after implantation (Fig. $5 \mathrm{~A}$ ). The experimental groups showed new bone formation in most of the defect (Fig. 5B).

FIG. 2. Effect of PRFe on the cellular proliferation, migration, and differentiation in vitro. (A) The percentage of BrdU incorporation was measured in control hABMSCs and PRFe-treated hABMSCs for proliferation evaluation. The relative numbers of BrdU-positive cells were increased about $40 \%$ by PRFe treatment, implying positive effect on cellular proliferation of PRFe. Cell nuclei were stained with 4',6'-diamidine-2'-phenylindole dihydrochloride and observed using a confocal microscope. Cells exhibiting BrdU incorporation in the nucleus were scored as BrdU-positive cells. Error bars indicate the standard deviations of three independent analysis. Scale bar was $100 \mu \mathrm{m}$. (B) Wound-healing assay showed inhibitory effect on the cellular migration. Confluent monolayers of cells were scratched to form wound and cultured in the absence or presence of $0.5 \%$ PRFe at the $0,12,24$, and $48 \mathrm{~h}$. The migration distances were measured between the leading edge and the wound line. After $24 \mathrm{~h}$, the cells in control group efficiently spread into the wound area, whereas few cells in PRFe-treated group spread forward. The migration rate was lower in the PRFe-treated group by $20 \%$ at $24 \mathrm{~h}$ and $19 \%$ at $48 \mathrm{~h}$ than in the control group. Error bars indicate the standard deviations of three independent analysis. Scale bar was $1 \mathrm{~mm}$. (C) The hABMSCs were grown under mineralization induction condition for 5 weeks with or without PRFe treatment and stained with Alizalin red. The mineral nodules stained in red (white arrows) were far more intense from the third week in the $0.5 \%$ PRFe-treated cells than in the control cells. Scale bar was $1 \mathrm{~mm}$. PRFe, PRF extract; hABMSCs, human alveolar bone marrow stem cells; BrdU, BromodeoxyUridine. 


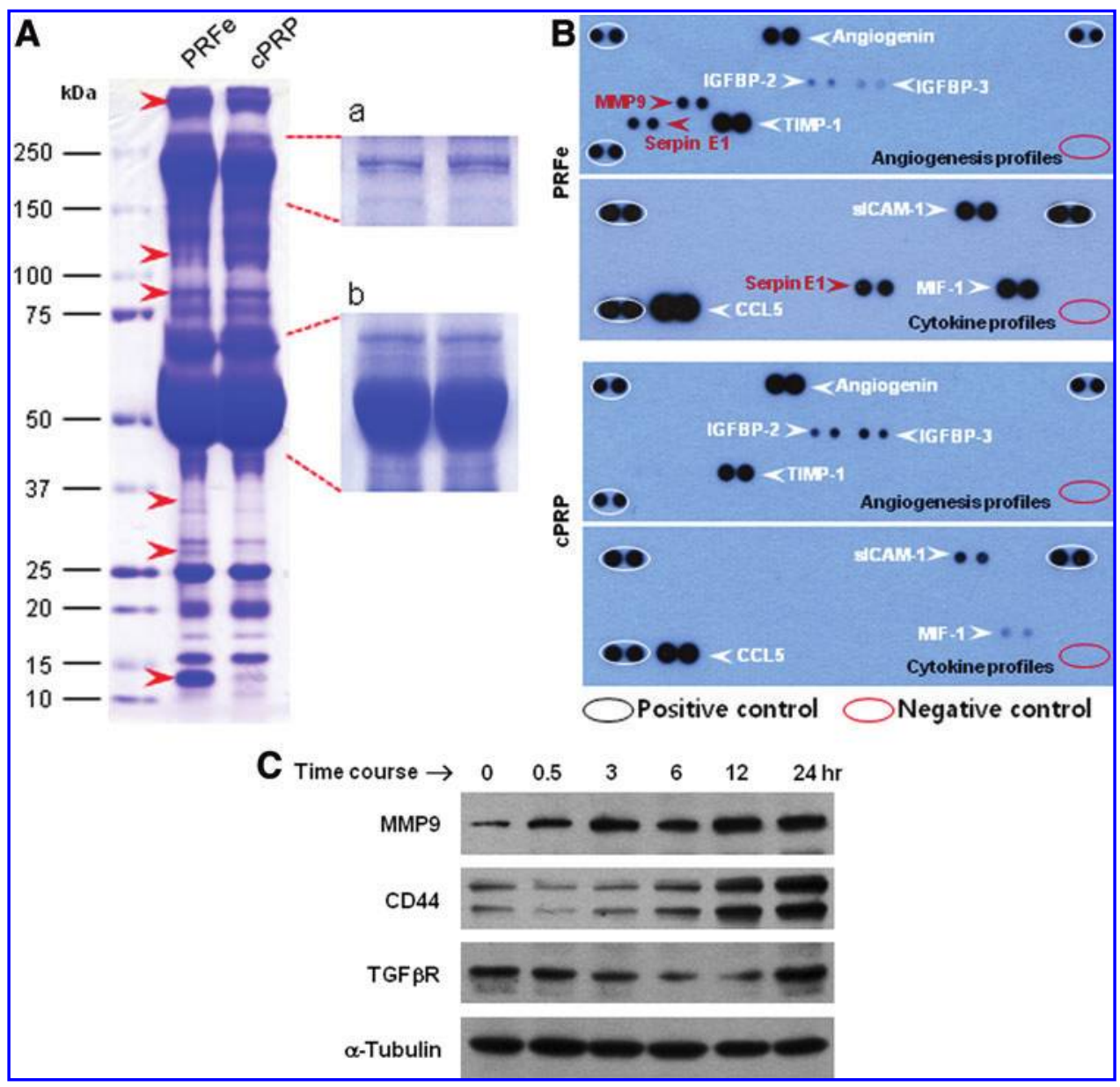

FIG. 3. Investigation of key molecules of PRFe. (A) Proteomic analysis of PRFe and cPRP. PRFe and cPRP were loaded on the gradient sodium dodecyl sulfate-polyacrylamide gel electrophoresis gel and the coomassie blue-stained bands were analyzed. Different band pattern was noticed between the PRFe and the CPRP and red arrow heads indicate some unique proteins in PRFe. For the highly concentrated protein bands at 250-150 and 60-45 kDa, both samples were 20 times diluted, reloaded, and shown as (a) and (b). (B) The human cytokines and angiogenesis-related proteins array kits revealed 7 factors that were highly expressed in both of PRFe and cPRP; angiogenin, IGFBP-2, IGFBP-3, TIMP-1, sICAM-1, MIF1, and RANTES/CCL5 among 36 cytokines and 55 angiogenesis-related proteins (white arrow heads). However, MMP9 and Serpin E1 were uniquely detected in PRFe, suggesting that MMP9 and Serpin E1 might play important roles in tissue regeneration. Array data were developed on X-ray films after exposure to chemiluminescent reagents. (C) Western blot showed the effects of PRFe on the activation of CD44 with simultaneous increase of MMP9 and TGF- $\beta 1$ receptor in hABMSCs at $24 \mathrm{~h}$ of treatment. PRFe was treated by $0.5 \%$ concentration in the indicated time course. $\alpha$-Tubulin was a loading control. cPRP, concentrated platelet-rich plasma. MMP9, matrix metalloproteinase 9; TGF- $\beta 1$, transforming growth factor- $\beta 1$. Color images available online at www.liebertonline.com/ten.

\section{Discussion}

The structural analysis of PRF was rarely performed but only an assumed illustration has been described. ${ }^{29}$ SEM observations of PRF combined with grafted cells were pictured and the microstructure of PRF has been described as fibrin meshes with enmeshed leukocytes. ${ }^{31}$ However, analysis of the fixed fresh PRF and its frozen form was never been performed. The fresh and the frozen PRF specimens showed two distinct zones, the zone of platelets and the zone of fibrin, which were shown for the first time in this study. (Fig. $1 \mathrm{~A}, \mathrm{C})$. The unique honeycomb structure of the frozen PRF contained many small spaces for housing of the future grafted cells (Fig. 1C). In some studies, clinical usage of PRF membrane was reported, which had been fabricated by simple compression of PRF. ${ }^{32}$ The unique microstructure of
PRF shown in this study well supported these scaffold characteristics of PRF, and therefore PRF can serve as an autologous bioscaffold to the surrounding hABMSCs, various cytokines, and growth factors in tissue regeneration.

The existence of platelets and fibrin were confirmed with the anti-platelet activity receptor antibody and the antifibronectin antibody (Fig. 1C). In the zone of fibrin, platelets and leukocytes were observed impinging inside the fibrin mesh and this constitution implied that various blood cells were capable of residing in PRF, secreting cytokines for longterm and thus contributing to tissue regeneration. Fibrin is known to play a vital structural role in the three-dimensional structural integrity of blood clots and by the simultaneous action of cytokines trapped in the meshes. ${ }^{33,34}$ Further, main angiogenesis soluble factors such as FGF, VEGF, angiopoietin, and PDGF were included in fibrin network. Previous 


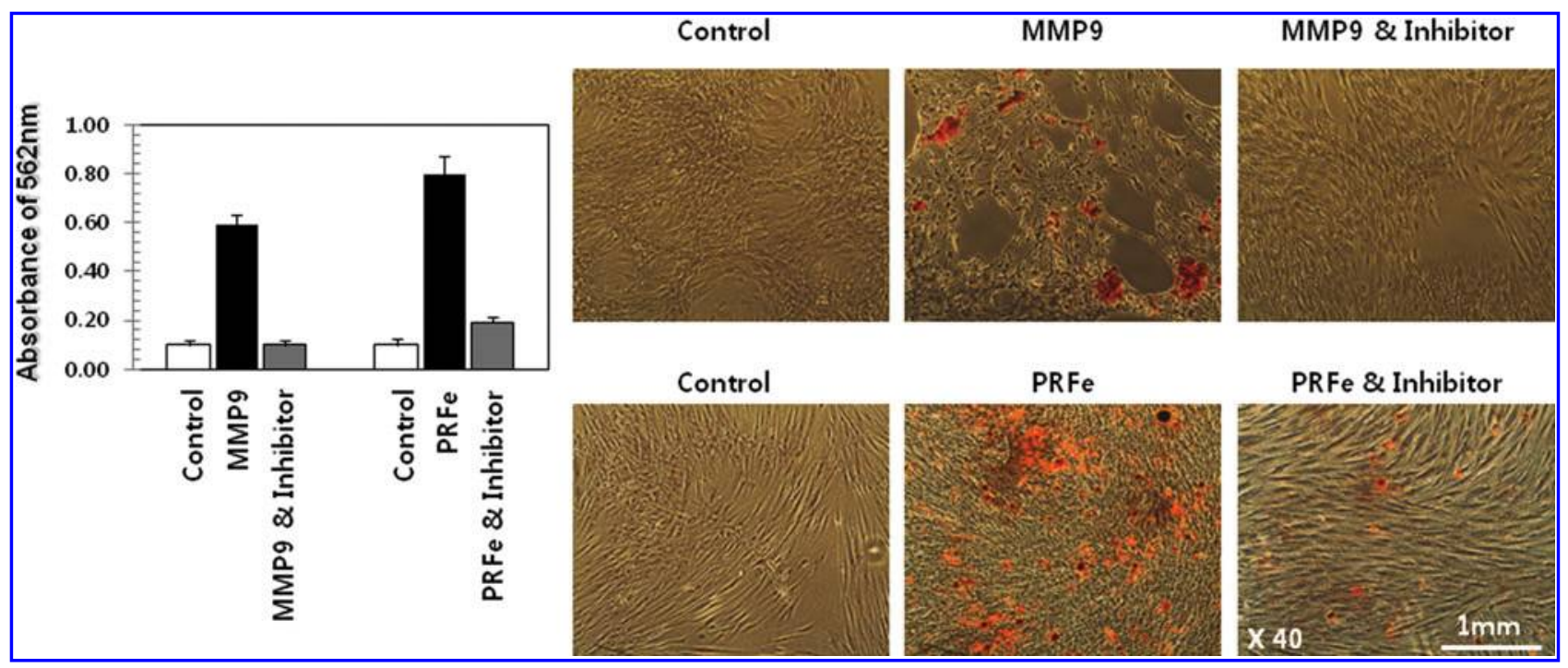

FIG. 4. Direct regulation of hABMSCs mineralization by MMP9. Mineralization of hABMSCs was enhanced by $40 \mathrm{ng} / \mathrm{mL}$ rMMP9 or $0.5 \%$ PRFe after 3 weeks of mineralization induction condition. The mineral nodules were stained in red by alizarin red (right panels). The hABMSCs cultured with rMMP9 plus $100 \mathrm{nM}$ MMP9 inhibitor showed reduced mineralization effect (the most right and upper panel). The same concentration of MMP9 inhibitor also reduced mineralization effect induced by $0.5 \%$ PRFe (the most right and lower panel). Scale bar was $1 \mathrm{~mm}$. The alizarin red-stained samples were destained as described in Materials and Methods, and the absorbance was measured at $562 \mathrm{~nm}$ (left graph). The trend of optical density value showed the similar effects MMP9 and its inhibitor on the alizarin red-stained hABMSCs. rMMP, recombinant MMP.

studies indicated that FGF and PDGF can bind to fibrin with high affinity. Therefore, direct fibrin angiogenesis induction could be explained by fibrin binding of numerous different growth factors. $^{23,24}$

Although the existence of various cytokines and numerous growth factors in PRF was shown in regenerated tissues, ${ }^{6-9}$ the physiological events between PRF and the surrounding stem cells remained uncertain. ${ }^{32}$ In this study, $0.5 \%$ PRFe increased proliferation of hABMSCs but decreased migration of the cells, which implied increased cel- lular aggregation. The proliferation and aggregation of the stem cells have to be preceded before cellular differentiation and the result of increased mineralization differentiation by PRFe confirmed this effect of PRF once again.

Analyzing the expression profiles of cytokines, chemokines, and angiogenesis-related proteins were essential and helpful in understanding the characteristics of PRF. TGF- $\beta 1$, PDGF-AB, VEGF, and thrombospondin-1 were the previously known growth factors released form PRF and proven to function positively for tissue regeneration. ${ }^{7,10-13}$ However,

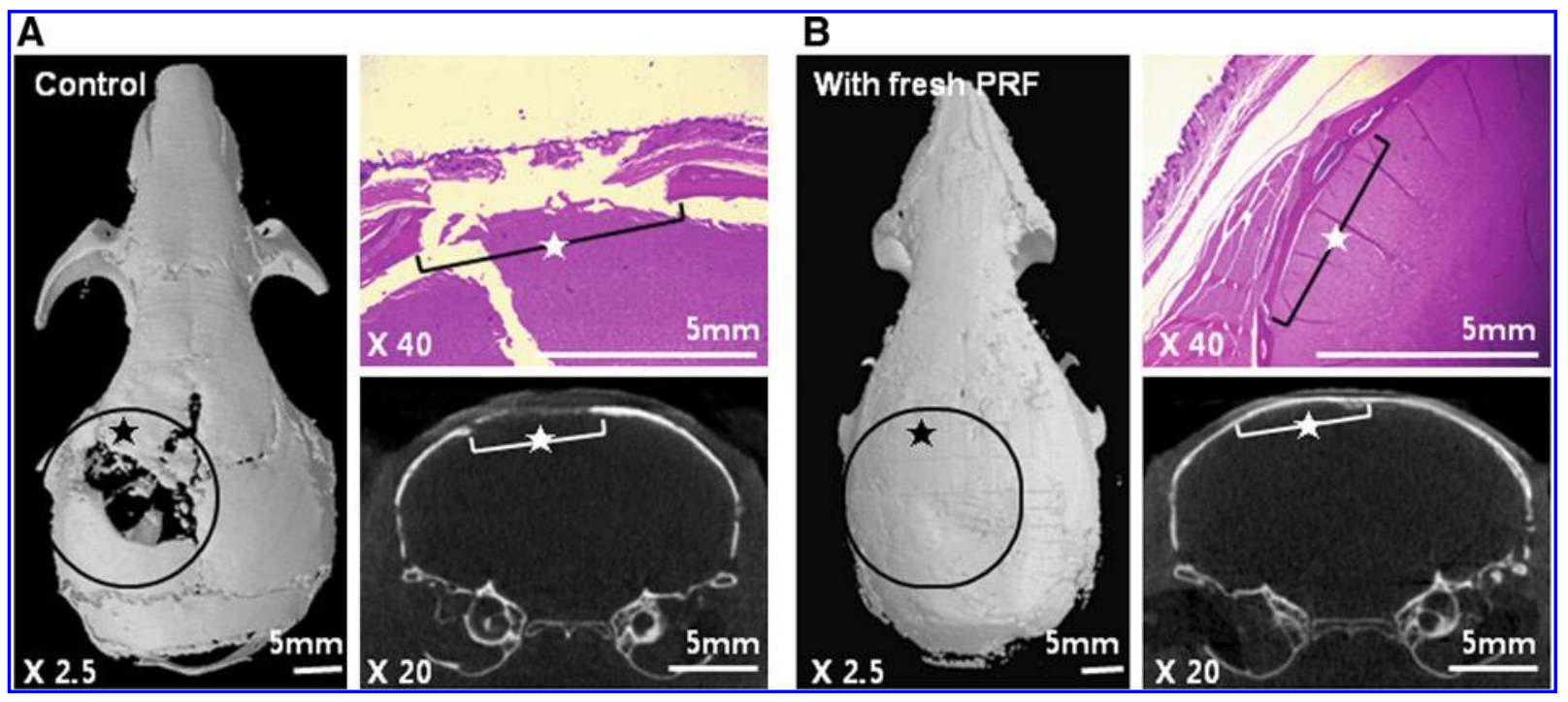

FIG. 5. Microcomputed tomography and histologic analysis of new bone formation in mouse calvarial defects. Hematoxylin and eosin- stained $4 \mu \mathrm{m}$ sections (asterisk represent defect margins) showed discontinued calvaria in control mouse (A), whereas the most filled bone defect in the fresh PRF-transplanted mouse (B). Three-dimensionally reconstructed and coronally sectioned microcomputed tomography images of calvarial defects clearly showed new bone formation in the experimental mouse in most of the defect in 8 weeks of healing. Scale bars were $5 \mathrm{~mm}$. 
MMP9 and SerpinE1 were the two distinguished factors detected only in PRF in this study and may play important roles in mechanisms of tissue regeneration (Fig. 3B). They were reported to involve in many biological processes such as cellular growth, differentiation, gene expression, migration, immunity, and inflammation. ${ }^{4-9,35-37}$

Between the two factors, MMP9 was prospected as one of the key factors in PRF for mineralization differentiation of hABMSCs. MMP9 has been reported to have close relation with osteopontin and CD44 in prostate cancer progression and metastasis. ${ }^{38-40}$ Osteopontin increases the migration of PC3 cells, the prostate cancer cells that metastasize to the bone tissue, and osteoclasts by increasing the surface expression of surface CD44. During this process, CD44 and MMP9 were known to form a complex on the cell surface. Therefore, we investigated a mechanism of MMP9 in PRF using immune blot, which revealed that PRFe simultaneously increased MMP9, CD44, and TGF- $\beta 1$ receptor at $24 \mathrm{~h}$ after $0.5 \%$ PRFe treatment (Fig. 3C). These results suggested that PRF were able to regulate proliferation and differentiation of hABMSCs by the three molecules. The direct regulation of mineralization by MMP9 shown in mineralization assay supported these results in the same trend (Fig. 4).

The fresh PRF transplantation group $(n=3)$ in the mouse calvarial critical-sized defect showed new bone formation in the most of the defect by 6 weeks of healing (Fig. 5B).

In this study, we investigated microstructure of PRF in the fresh form and the frozen form and suggested their characteristic of bioscaffold. It was biochemically and physiologically evident that PRF increased proliferation, aggregation, and mineralization by decreasing migration of the hABMSCs. PRF contained Angiogenin, IGFBP-2, IGFBP-3, Serpin E1, TIMP-1, sICAM-1, MIF1, and RANTES/CCL5, which were identified by proteome arrays, but MMP9 and SerpinE1 were the two distinguished factors expressed only in PRFe compared to cPRP. Activation of MMP9 in PRFe-regulated cellular differentiation via CD44. Our results demonstrate that PRF is a simple and strong enhancer for tissue regeneration and thus can be efficiently used in clinical medicine and dentistry.

\section{Acknowledgments}

This work was supported by a grant from the National Research Foundation of Korea (NRF) funded by the Korea government (MEST) (No. 2009-0066366) to P.H.C.

\section{Disclosure Statement}

No competing financial interests exist.

\section{References}

1. Marx, R.E., Carlson, E.R., Eichstaedt, R.M., Schimmele, S.R., Strauss, J.E., and Georgeff, K.R. Platelet-rich plasma: growth factor enhancement for bone grafts. Oral Surg Oral Med Oral Pathol Oral Radiol Endod 85, 638, 1998.

2. Dohan, D.M., Choukroun, J., Diss, A., Dohan, S.L., Dohan, A.J., Mouhyi, J., and Gogly, B. Platelet-rich fibrin (PRF): a second-generation platelet concentrate. Part I: technological concepts and evolution. Oral Surg Oral Med Oral Pathol Oral Radiol Endod 101, e37, 2006.

3. Mazor, Z., Horowitz, R.A., Del Corso, M., Prasad, H.S., Rohrer, M.D., and Dohan Ehrenfest, D.M. Sinus floor aug- mentation with simultaneous implant placement using Choukroun's platelet-rich fibrin as the sole grafting material: a radiologic and histologic study at 6 months. J Periodontol 80, 2056, 2009.

4. Choukroun, J., Diss, A., Simonpieri, A., Girard, M.O., Schoeffler, C., Dohan, S.L., Dohan, A.J., Mouhyi, J., and Dohan, D.M. Platelet-rich fibrin (PRF): a second-generation platelet concentrate. Part IV: clinical effects on tissue healing. Oral Surg Oral Med Oral Pathol Oral Radiol Endod 101, e56, 2006.

5. Choukroun, J., Diss, A., Simonpieri, A., Girard, M.O., Schoeffler, C., Dohan, S.L., Dohan, A.J., Mouhyi, J., and Dohan, D.M. Platelet-rich fibrin (PRF): a second-generation platelet concentrate. Part V: histologic evaluations of PRF effects on bone allograft maturation in sinus lift. Oral Surg Oral Med Oral Pathol Oral Radiol Endod 101, 299, 2006.

6. Dohan, D.M., Choukroun, J., Diss, A., Dohan, S.L., Dohan, A.J., Mouhyi, J., and Gogly, B.L. Platelet-rich fibrin (PRF): a second-generation platelet concentrate. Part III: leucocyte activation: a new feature for platelet concentrates? Oral Surg Oral Med Oral Pathol Oral Radiol Endod 101, e51, 2006.

7. Dohan, D.M., Choukroun, J., Diss, A., Dohan, S.L., Dohan, A.J., and Mouhyi, J. Platelet-rich fibrin (PRF): a secondgeneration platelet concentrate. Part II: platelet-related biologic features. Oral Surg Oral Med Oral Pathol Oral Radiol Endod 101, e45, 2006.

8. Dohan Ehrenfest, D.M., de Peppo, G.M., Doglioli, P., and Sammartino, G. Slow release of growth factors and thrombospondin-1 in Choukroun's platelet-rich fibrin (PRF): a gold standard to achieve for all surgical platelet concentrates technologies. Growth Factors 27, 63, 2009.

9. Lorenzo, J., Horowitz, M., and Choi, Y. Osteoimmunology: interactions of the bone and immune system. Endocr Rev 29, 403, 2008.

10. Pierce, G.F., Mustoe, T.A., Altrock, B.W., Deuel, T.F., and Thomason, A. Role of platelet-derived growth factor in wound healing. J Cell Biochem 45, 319, 1991.

11. Bolander, M.E. Regulation of fracture repair by growth factors. Proc Soc Exp Biol Med 200, 165, 1992.

12. Cromack, D.T., Porras-Reyes, B., and Mustoe, T.A. Current concepts in wound healing: growth factor and macrophage interaction. J Trauma 30, S129, 1990.

13. Dohan Ehrenfest, D.M., de Peppo, G.M., Doglioli, P., and Sammartino, G. Slow release of growth factors and thrombospondin-1 in Choukroun's platelet-rich fibrin (PRF): a gold standard to achieve for all surgical platelet concentrates technologies. Growth Factors 27, 63, 2009.

14. Dohan, D.M., and Choukroun, J. PRP, cPRP, PRF, PRG, PRGF, FC ... How to find your way in the jungle of platelet concentrates? OraSurg Oral Med Oral Pathol Oral Radiol Endod 103, 305, 2007.

15. Dugrillon, A., Eichler, H., Kern, S., and Klüter, H. Autologous concentrated platelet-rich plasma (cPRP) for local application in bone regeneration. Int J Oral Maxillofac Surg 31, 615, 2002.

16. Marx, R.E., Carlson, E.R., Eichstaedt, R.M., Schimmele, S.R., Strauss, J.E., and Georgeff, K.R. Platelet-rich plasma: growth factor enhancement for bone grafts. Oral Surg Oral Med Oral Pathol Oral Radiol Endod 85, 638, 1998.

17. Shanaman, R., Filstein, M.R., and Danesh-Meyer, M.J. Localized ridge augmentation using GBR and platelet-rich plasma: case reports. Int J Periodontics Restorative Dent 21, 345, 2001.

18. Schlegel, K.A., Donath, K., Rupprecht, S., Falk, S., Zimmermann, R., Felszeghy, E., and Wiltfang, J. De novo bone for- 
mation using bovine collagen and platelet-rich plasma. Biomaterials 25, 5387, 2004.

19. Thorwarth, M., Rupprecht, S., Falk, S., Felszeghy, E., Wiltfang, J., and Schlegel, K.A. Expression of bone matrix proteins during de novo bone formation using a bovine collagen and platelet-rich plasma (PRP)—an immunohistochemical analysis. Biomaterials 26, 2575, 2005.

20. He, L., Lin, Y., Hu, X., Zhang, U., and $\mathrm{Wu}, \mathrm{H}$. Comparative study of platelet-rich fibrin (PRF) and platelet-rich plasma (PRP) on the effect of proliferation and differentiation of rat osteoblasts in vitro. Oral Surg Oral Med Oral Pathol Oral Radiol Endod 108, 707, 2009.

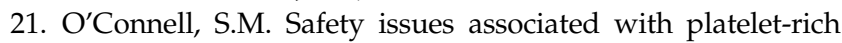
fibrin method. Oral Surg Oral Med Oral Pathol Oral Radiol Endod 103, 587, 2007.

22. Cowan, C.M., Shi, Y.Y., Aalami, O.O., Chou, Y.F., Mari, C., Thomas, R., Quarto, N., Contag, C.H., Wu, B., and Longaker, M.T. Adipose-derived adult stromal cells heal critical-size mouse calvarial defects. Nat Biotechnol 22, 560, 2004.

23. Sahni, A., Odrljin, T., and Francis, C.W. Binding of basic fibroblast growth factor to fibrinogen and fibrin. J Biol Chem 273, 7554, 1998.

24. Dohan Ehrenfest, D.M., Rasmusson, L., and Albrektsson, T. Classification of platelet concentrates: from pure platelet-rich plasma (P-PRP) to leucocyte- and platelet-rich fibrin (L-PRF). Trends Biotechnol 27, 158, 2009.

25. Yu, Q., and Stamenkovic, I. Localization of matrix metalloproteinase 9 to the cell surface provides a mechanism for CD44-mediated tumor invasion. Genes Dev 13, 35, 1999.

26. Karadag, A., Fedarko, N.S., and Fisher, L.W. Dentin matrix protein 1 enhances invasion potential of colon cancer cells by bridging matrix metalloproteinase- 9 to integrins and CD44. Cancer Res 65, 11545, 2005.

27. Desai, B., Rogers, M.J., and Chellaiah, M.A. Mechanisms of osteopontin and CD44 as metastatic principles in prostate cancer cells. Mol Cancer 6, 18, 2007.

28. Samanna, V., Ma, T., Mak, T.W., Rogers, M., and Chellaiah, M.A. Actin polymerization modulates CD44 surface expression, MMP-9 activation, and osteoclast function. J Cell Physiol 213, 710, 2007.

29. Dohan Ehrenfest, D.M., Rasmusson, L., and Albrektsson, T. Classification of platelet concentrates: from pure platelet-rich plasma (P-PRP) to leucocyte- and platelet-rich fibrin (L-PRF). Trends Biotechnol 27, 158, 2009.

30. Whitman, D.H., Berry, R.L., and Green, D.M. Platelet gel: an autologous alternative to fibrin glue with applications in oral and maxillofacial surgery. J Oral Maxillofac Surg 55, 1294, 1997.

31. Dohan Ehrenfest, D.M., Diss, A., Odin, G., Doglioli, P., Hippolyte, M.P., and Charrier, J.B. In vitro effects of Choukroun's PRF (platelet-rich fibrin) on human gingival fibroblasts, dermal prekeratinocytes, preadipocytes, and maxillofacial osteoblasts in primary cultures. Oral Surg Oral Med Oral Pathol Oral Radiol Endod 108, 341, 2009.

32. Aroca, S., Keglevich, T., Barbieri, B., Gera, I., and Etienne, D. Clinical evaluation of a modified coronally advanced flap alone or in combination with a platelet-rich fibrin membrane for the treatment of adjacent multiple gingival recessions: a 6-month study. J Periodontol 80, 244, 2009.

33. Wolberg, A.S. Thrombin generation and fibrin clot structure. Blood Rev 21, 131, 2007.

34. van Hinsbergh, V.W., Collen, A., and Koolwijk, P. Role of fibrin matrix in angiogenesis. Ann NY Acad Sci 936, 426, 2001.

35. Ouyang, H., McCauley, L.K., Berry, J.E., D’Errico, J.A., Strayhorn, C.L., and Somerman, M.J. Response of immortalized murine cementoblasts/periodontal ligament cells to parathyroid hormone and parathyroid hormone-related protein in vitro. Arch Oral Biol 45, 293, 2000.

36. Ohno, S., Doi, T., Fujimoto, K., Ijuin, C., Tanaka, N., Tanimoto, K., Honda, K., Nakahara, M., Kato, Y., and Tanne, K. RGD-CAP (betaig-h3) exerts a negative regulatory function on mineralization in the human periodontal ligament. J Dent Res 81, 822, 2002.

37. Marcopoulou, C.E., Vavouraki, H.N., Dereka, X.E., and Vrotsos, I.A. Proliferative effect of growth factors TGF-beta1, PDGF-BB and rhBMP-2 on human gingival fibroblasts and periodontal ligament cells. J Int Acad Periodontol 5, 63, 2003.

38. Thalmann, G.N., Sikes, R.A., Devoll, R.E., Kiefer, J.A., Markwalder, R., Klima, I., Farach-Carson, C.M., Studer, U.E., and Chung, L.W. Osteopontin: possible role in prostate cancer progression. Clin Cancer Res 5, 2271, 1999.

39. Ishimaru, H., Kageyama, Y., Hayashi, T., Nemoto, T., Eishi, Y., and Kihara, K. Expression of matrix metalloproteinase-9 and bombesin/gastrin-releasing peptide in human prostate cancers and their lymph node metastases. Acta Oncol 41, 289, 2002.

40. Hara, T., Miyazaki, H., Lee, A., Tran, CP., and Reiter, R.E. Androgen receptor and invasion in prostate cancer. $\underline{\text { Cancer }}$ $\underline{\text { Res }}$ 68, 1128, 2008.

Address correspondence to: Pill-Hoon Choung, D.D.S., Ph.D.

Department of Oral and Maxillofacial Surgery Dental Research Institute School of Dentistry Seoul National University 28 Yeongeon-dong Jongno-gu Seoul 110-749

Korea

E-mail: cph@plaza.snu.ac.kr

Received: June 4, 2010 Accepted: August 27, 2010

Online Publication Date: December 21, 2010 



\section{This article has been cited by:}

1. Ki-Taek Lim , Jangho Kim , Hoon Seonwoo, Jung Uk Chang, Hwajung Choi , Jin Hexiu, Woo Jae Cho , Pill-Hoon Choung , Jong Hoon Chung . 2013. Enhanced Osteogenesis of Human Alveolar Bone-Derived Mesenchymal Stem Cells for Tooth Tissue Engineering Using Fluid Shear Stress in a Rocking Culture Method. Tissue Engineering Part C: Methods 19:2, 128-145. [Abstract] [Full Text HTML] [Full Text PDF] [Full Text PDF with Links]

2. Bérengère Chignon-Sicard, Charalambos A. Georgiou, Eric Fontas, Sylvain David, Pierre Dumas, Tarik Ihrai, Elisabeth Lebreton. 2012. Efficacy of Leukocyte- and Platelet-Rich Fibrin in Wound Healing. Plastic and Reconstructive Surgery 130:6, 819e-829e. [CrossRef]

3. R. Vinaya Kumar, N. Shubhashini. 2012. Platelet rich fibrin: a new paradigm in periodontal regeneration. Cell and Tissue Banking . [CrossRef]

4. Xuetao Xie, Yang Wang, Cunju Zhao, Shangchun Guo, Shen Liu, Weitao Jia, Rocky S. Tuan, Changqing Zhang. 2012. Comparative evaluation of MSCs from bone marrow and adipose tissue seeded in PRP-derived scaffold for cartilage regeneration. Biomaterials 33:29, 7008-7018. [CrossRef]

5. James H-C. Wang, Qianping Guo, Bin Li. 2012. Tendon Biomechanics and Mechanobiology-A Minireview of Basic Concepts and Recent Advancements. Journal of Hand Therapy 25:2, 133-141. [CrossRef]

6. Alfred Seban, Patrick BonnaudApplications cliniques des augmentations du volume osseux à visée implantaire 299-435. [CrossRef]

7. Timothy E. L. Douglas, Volker Gassling, Heidi A. Declercq, Nicolai Purcz, Elzbieta Pamula, Håvard J. Haugen, Safak Chasan, Eric L. W. de Mulder, John A. Jansen, Sander C. G. Leeuwenburgh. 2012. Enzymatically induced mineralization of plateletrich fibrin. Journal of Biomedical Materials Research Part A n/a-n/a. [CrossRef]

8. Yoshitaka Fukaya, Masayuki Kuroda, Yasuyuki Aoyagi, Sakiyo Asada, Yoshitaka Kubota, Yoshitaka Okamoto, Toshinori Nakayama, Yasushi Saito, Kaneshige Satoh, Hideaki Bujo. 2012. Platelet-rich plasma inhibits the apoptosis of highly adipogenic homogeneous preadipocytes in an in vitro culture system. Experimental \& Molecular Medicine 44:5, 330. [CrossRef]

9. Mogammad Thabit Peck, Johan Marnewick, Lawrence Stephen. 2011. Alveolar Ridge Preservation Using Leukocyte and Platelet-Rich Fibrin: A Report of a Case. Case Reports in Dentistry 2011, 1-5. [CrossRef] 